('orrectly in a majority of such sequences, the interval would be reduced. Many correct replies were given on intervals of one and two vibrations, and a few could discern the higher of two tones having an interval of only half a viluration. However, the lowest interval on which an individual Indian could be considered sure in his perception was three vibrations, or one-eighteenth of a tone. Others showed a limit in pitch discrimination of five vibrations, or one-eleventh of a tone.

The method used in these tests was that of Prof. C. E. Seashore, of the State University of Iowa, who kindly examined the record of the tests and expressed the opinion that the abilities shown by the Indians were about as good as would be found among average American whites under similar conditions.

This is a subject for further investigation, and is one of the many questions which open large and full of interest to the student of Indian music.

\title{
Light Projection
}

\section{A Short History of Its Evolution and Devices Employed}

\author{
By C. A. Halvorson, Jr., and R. B. Hussey
}

Ligut projection has been the subject of several jaluers within the last year or two and it would seem that the theoretical principles involved and the present practice had been well covered. Accordingly, something on the history and development of light projection or control of light may be of interest.

Any redirection of a beam of light is a form of control or projection. Such redirection may be accomplisher loy reflection or by refraction or both. In minciples, looth of these have been understood and to some extent used for many centuries.

The Book of Job, which is perhaps one of the ellest extant writings in the world, mentions molten looking ylasses or mirrors.

The Egyptian women in the time of Moses used mir rors in connection with the worship of their idols as well as perhaps for more secular purposes, and there in the museums.

One of the earliest mentions of the use of a lens is found in a play produced at Athens in 424 B. C., where .ristophanes alludes to the use of a burning glass in the following manner:

Comedy of the Clocus.-Act 2.

S'repsiades-You have seen at the druggist's that fine transparent stone with which fires are kindled?

Socrutes-You mean glass, do you not?

strep.-Tust so.

Soe.- Well what will you do with that?

strep.-When a summons is sent to me I will take

this stone, and placing myself in the sun, I will.

though at a distance. melt all the writing of the summons.

'The writing was then traced on wax spread over a solid substance.)

Then there is a well-known tradition that Archimedes used mirrors to concentrate the rays of the sun, thereby setting fire to the Roman ships that were besieging the (ity of Syracuse in $212 \mathrm{~B}$. C.

Fuclid. the celebrated geometer, who lived in the third century, B. C.. is credited with the authorship of a treatise on optics which takes up ameng other matters the reflection of light from concave spherical mirrors and alludes to setting fires by the sun's rays.

. Inother name that stands out prominently in the list of philosophers to study the subject of light and light control is that of Claudius Ptolemieus, better known as the Alexandrian Ptolemy. In common with most of these early philosophers, his chief interest was along the lines of astronomical research and his work on light was lone with such investigations in mind. His writings on optics treat of the refraction of luminous rays in their passage through media of different densities. His mea surements of refraction at different angles furnish the oldest extant example of an accurately conducted physical investigation by experiment.

Inother prominent investigator was Alhazen, who livel in Arabia in the eleventh century, $A$. D. He cridently had access to the writings of Ptolemy and carlier astronomers and compiled their works, adding investigations of his own.

The manufacture and properties of simple lenses were beginning to be understood at this time, and from the work of Alhazen and that of ritellio in Poland in the thirteenth century came the irlea of using spectacles. It was not, however, until nearly the end of the thirteenth century that spectacles came into anything like common use.

John Peckham, Archbishop of Canterbury, who died in 1292. mentions mirrors made of steel, iron, polished marble and of glass covered on the back with lead. 'These last were made by pouring melted lead on hot glass plates. Mirrors of glass, coated with an amalmam of tin and mercury. were made by the Venetians in the sixteenth century.

*A paper presented linfore the New Jork Section of the Iluminating renginering socints, and republished by permission froun the Transeretions of the societs.
Although the invention of the telescope has been claimed for several different men, it is probable that the credit should be given to Hans Lippershey. a spectacle maker of Holland, who described his invention and asked exclusive selling rights in 1608 . Galileo heard of this invention and proceeded to make one himself the following year and later made numerous improvements in design.

Although many men had investigated the refraction of light, back as far Ptolemy, no one had recognize Snell, in 1621, succeeded in establishing the principle and expressing it in the form since known as Snell Law, which states that the ratio of the sines of the angles of incidence and refraction is a constant for given media.

It is of peculiar interest just at the present time to remember that the German astronomer Hevelius, who died in 1684, invented a lens device for use in war, which he called a polemoscope and which was essen tially the same as the trench periscope of today.

Iuygens of IIolland in 1678 was the first to express in definite form the wave theory of light. A few years later Huygens satisfactorily explained the principles of reflection and refraction. He also discovered polariration, but could not account for it. This same IIuygens, it may be noted, manufactured lenses and tele scopes and also, about the middle of the seventeenth (entury, invented the pendulum clock.

A history of the art or science of lighting would be incomplete without some mention of the work of Sir Isaac Newton (1642-1727). His most notable discovery was the. composition of light and production of a spectrum by dispersion through a prism. At this distance it seems strange that he did not get a clearer idea of the nature of light, as he maintained to the last that light consisted of an emanation of material particle (the corpuscular theory). Newton also devised method of studying the dependence of colors of thin films upon the thickness of the film and made, if not the first at least one of the first, reflecting telescopes. Probably this was the very first reflecting telescope to be used for actual astronomical work.

During the eighteenth century a number of developments in the theoretical investigation of light and in the design of optical apparatus were made.

As early as 1745 , it is said that reflectors of som sort were used on street lanterns, and Lavoisier, the famous chemist and physicist, investigated the properties of such reflectors. The only mention of reflected light earlier than this that we have been able to find was the concentrating lantern alluded to by Pepys about the middle of the seventeenth century. It seems strange that some lens or reflector lighting units were not devised before this time, inasmuch as candles and $\bullet$ lamps were in common use and the properties of simple lenses and concave reflectors were well understood.

Dollond in 1757 was the first to make and describe achromatic combinations of lenses by using glasses of lifferent qualities, although the principle and some of the possibilities were described by a man by the name of Hall about twenty years earlier.

Lavoisier in 1774 made a lens of about 4 feet $(1.2 \mathrm{~m}$.) in diameter. using two concave glasses put together a the edges and filled with water or other fluids. With a lens of this type it was possible to not merely ignite wood in the sun's rays, but even to melt metals. Buffon made up a compound mirror of several hundred plane mirrors, each about 6 inches by 4 inches ( 15 by $20 \mathrm{~cm}$.) mounte in a large frame so as to approximate a para bolic mirror. With this he succeeded in setting fire to wood at a distance of 210 feet $(64 \mathrm{~m}$.), demonstrating the possibility of Archimedes having set fire to the Roman ships in this manner. Buffon also proposed in 1748 to make a lens out of a solid piece of glass ground in steps or concentric zones so as to reduce the thickness to a minimum. This was similar to the designs worked out by Fresnel some 70 years later.

As early as 1763, parabolic reflectors consisting of small facets of silvered glass set in plaster of Paris were used in some of the lighthouses on the Mersey. Spherical metallic mirrors were introduced into France in 1781 and were followed by parabolic reflectors of silvered copper in 1790

Fresnel, who began his optical work about 1814 . introduced the conception of transverse light waves and harmonized the former theories and observed phenomena. He was able to explain reflection, refraction, polarization and interference on this basis. He also made notable advances in the art of reflector design and construction, working out the sectional lensprism system bearing his name.

In 1825 Drummond conceived the idea of using as a source of light a piece of lime or similar oxide heated to incandescence in a blast flame. He finally worked out the "lime light," using an oxyhydrogen flame on a cylinder of lime and adapted the lamp to searchlight and stereopticon work. According to Professor Elihu Thomson, the first floodlighting was doubtless done about this time in theatres using units of this kind. although the first electric arc to be used in theatrical work is not recorded until 1846 in Paris. The first searellamp to be used in war is said to have been 'a Drummond limelight outfit used in the attack on Fort Wagner, Charleston, in the fall of 1863 .

In 1848 the first electric arc lamp for general illumination was installed in Paris, using a huge voltaic battery to supply the current. The public were amazed at the powerful clear white light, and many fanciful predictions were made of cities illuminated in the future by these lamps, and even a city lighted by a single lamp of immense candlepower suspended high in the air. Soon after the middle of the century, the electric: arc lamp was developed to a commercial point, providing a practical light source of high intensity and great brilliancy. This gave fresh impetus to the study and design of light-projecting apparatus. The arc searchlamp soon became a commercial article and has been improved and elaborated upon until at the present time arc searchlamps are available in many sizes and consuming from about 10 to several hundred amperes. with parabolic mirrors up to 6 or 7 feet (1.8 to $2.1 \mathrm{~m}$.) in diameter, and giving light beams of hundreds of millions of candlepower.

The most notable advance of recent years in the design of arc searchlamps is due to Beck, who invented the intensive flame carbon are searchlamp. In the endeavor to produce higher intensities by increasing the current through the arc, it was found that a very heavy current produced flaming and unsteadiness. The intense heat caused the carbons to crumble away rapidy unless a carbon of very large diameter was used, which produce unsteadiness of operation and poor focusing. By directing a stream of alcohol vapor or other nonoxidizing gas, the carbons could be kept cooler on the outside and prevented from wasting. This made it possible to operate much greater current densities and accordingly obtain much higher beam intensities. The light is further increased by the use of carbons corel with certain metallic salts and greater steadiness and uniformity is obtained by rotating the earbons.

In connection with the commercial development of the parabolic mirror, it was found that the manufacture of reflectors with a true parabolic curvature was difficult and expensive. while a spherical shape could le obtained much easier. Accordingly, Mangin in 1874 devised a reflector of glass in which both inner and outer surfaces were spherical, but of different radii, so that the reflector was thicker at the edge than at the middle. By proportioning the radii of curvature correctly, the refraction of light through the glass, made up for the spherical aberration from the surface and an approximately parallel beam of light resulted. These mirrors give fairly good results, but are not as true or as efficient as the parabolic mirrors. although much less expensive.

In the design of lighthouse equipment the results are usually attained by the use of carefully ground eptical 
glass prisms or prism-lenses, after Fresnel's general plan. but much improved since his time. The optical system of a lighthouse unit consists of the central lens or set of lenses arranged in zones known as the dioptric system, and outside of these a set of prisms known a the catadioptric elements, which depend upon both refraction and total internal reflection. In some cases a set of totally reflecting prisms also is used on one side of the light source to reflect all the light emitted in that direction back through or near the source and increase the intensity in the opposite direction.

Several United States patents, issued in 1853 and 1859. relate to special arrangements of parabolic and conic reflectors and simple lenses, particularly for lantern work. A patent issued in 1859 discloses a combination of an ellipsoid with a paraboloid. A number of interesting arrangements of multiple prisms and reflectors are described in the patent to Skelton in 187. while the patents to $\mathrm{W}$ Wheeler in 1881 and 1882 show some peculiar and complex reflectors made by combining two or three conic curves in a single reflector. Infortunately, little commercial success was realized from this work, largely perhaps on account of the fact that a concentrate focusing light source with satisfactory operation was not available at that time. Then tom. while the principles of light measurement were understood, the science of photometry was but little leveloped and the distribution of the flux about the (r)mmon light sources was not known and little attempt had been made to utilize the largest possible propor tion of the emitted light. Mention should also be made of the prismatic glass devices of A. P Trotter, patented in 1885, and of Blonfel and P'saroudaki in 1896 these representing the fundamental principles of the prismatic glassware now so commonly used.

Although floodlighting by the use of projector lamps with concentrating reflectors may be said in one way to date from the first commercial searchlamps. before the middle of the last century, it has not been practiced to any considerable extent, except for temporary and spectacular purposes, until the last two or three years. Occasionally some particular point of interest was tem norarily illuminated, but little was thought of such illumination for continued operation. On the occasion of a celebration in London, in February, 1872, an at tempt was made to illuminate the dome of St. Paul's Cathedral by the use of a large number of ship lan terns, but the result was very unsatisfactory. Commenting on this. a London magazine made the following statement:

"Perhaps the most practicable way of effectually illuminating St. Paul's would consist in fiooding it with electric light projected from various quarters."

Considering the illumination of a monument, $\mathrm{Dr}$ Louis Bell writes, in 1902, as follows :

"About the only way of getting any effective illumination at the top of the monument is to use focusing lamps with projectors. Three or four of these mounted symmetrically about the object to be lighted at any convenient distance will come as near an effective illumination as one may expect to get. Their beams should be inclined upwards enough to keep them effectively out of the field of vision and the rest of the monument, if of light stone, should be left to itself. $t$ figure wholly light in tone can be very beautifully A figure wholly light in tone can be very beautifully
illuminated by such means, but if of bronze or similar dark material, e. g., the great Bartholdi Liberty. adequate illumination is both very difficult and, if suc cessful, decidedly expensive."

The last sentence is of peculiar interest in view of the recent illumination of this same Statue of Liberty with a permanent installation of incandescent projectors.

In the summer of 1906, W. D.'A. Ryan conducted numerous experiments at Nahant, Mass., along the lines of spectacular lighting of clouds of steam, presagin the color scintillator used later at the Hudson-Fulton Celebration and at San Francisco, also illuminating a large American flag suspended over a street, using a battery of about ten arc searchlamps. The following year Ryan installed a large battery of these searchlamps at Niagara, illuminating both the American and Canadian Falls. Colored screens in front of the projectors provided a means of obtaining a wide variety of color effects at will, and the whole resulted in a very unique and pleasing display. As early as 1908, the tower of the Singer Building in New York City, the loftiest city building in the country at that time, wa illuminate by Ryan by means of arc searchlamps.

Although the best results from the point of view of intensity and color have been obtained with arc lamps and ane projectors, the complication and the necessity of an electrically-operated mechanism or of manual control of some sort makes such a system too expensive or common use.

Three factors in particular served to prepare the way for general fioodlighting. 'The first of these was the installation of ornamental magnetite arc lamps in New Haven, Conn., in 1911; the first intensive downtown lighting or "white way" system adopted in this country or elsewhere. With this system not only was the street lighted to a relatively high intensity without glare, but the building fronts and façades and cornices of ninestory blocks were beautifully illuminate in all their details.

The second factor was the wonderfully beautiful lighting effects produce by W. D'A. Ryan at the San Francisco Exposition by the use of powerful light sources, arc, ineandescent and gas, with and without reflectors; but every brilliant source was screened from view, the entire Exposition being painted, as it were, with light from invisible sources.

And third the introduction of the concentrated filament gas-tilled incandescent lamp, making possible the development of simple efficient and easily handled projector units of comparatively low cost. The first floo lighting projectors using these lamps were made little more than two rears ago, and many designs and different forms and sizes have been developed and used since that time.

With the exception of this gas-filled concentrated filament ineandescent lamp, the other raw materials now available to the designing engineer are the same as for a number of years past. The chemical depos tion of silver on glass replacing the mercury-tin ama gam dates back to 1843 , while sheet aluminum has been used for about 25 years.

In projection of light or light control, almost any desired effect or kind of distribution can be produce if the purchaser is willing to pay for it. Polishe lenses are used in cases where the greatest accuracy or maximum effect must be had, as in telescopes and the like, also in lighthouses and to a great extent in stereopticon work. Optically ground and polished prisms are also use in lighthouse work. A cheape grade of prisms, known as holophane, pressed, but not ground, yet of high transmission, are used extensively in street and interior illumination, where the cost is considerable factor and where the greatest accuracy is unnecessary. Iresse glass, silvered, is also use in large quantities in interior lighting. Many different materials are used for reflecting surfaces by different designers, such as aluminum, nickel, silver and gold plate. silvere glass, aluminum bronze paint, porcelain enamel and even flat white paint. Then, too, the designer of present day lighting projectors may use a will any of the conic sections as parabola, hyperbola ellipse, circle or any combination of these, in the desig of a reflector, or even an arrangement of many small plane mirrors placed so as to roughly approximate given curve. This last serves to spread the light more widely and also more uniformly than a single, simple curve would do using ordinary commercial materials. The automobile headlamp is another phase of ligh projection upon which much time and energy has bee devoted during the last few years. Muoh work ha been done by persons apparently unacquainted with the principles of light control, resulting in many inefficient and theoretically incorrect devices. Every known optical principle has been used in the attempt to accomplish a very simple result. It may be said in this connection that if it could be definitely agreed just what lighting effect would be the most satisfactory and desirable, a device could be made to produce that effect There are today many opinions on this point and accordingly many devices on the market.

Aside from whatever is accomplished with the automobile headlamp, there is an obvious solution of the problem which apparently has escaped the majority of illuminating experts, namely, the illumination of the roadway. Considering Massachusetts alone, a rough computation shows that the same lumen output, or the same generating capacity as is now used for automobile headlighting, if used for street lighting, would illuminate approximately 10,000 miles of highway to a fairly satisfactory degree. These results could be accomplished only through the principles of scientific projection, and this point is mentione here only to give some idea of the possibilities of development along these lines. If the same expenditure of human effort and money were directed toward the accomplishment of this most desirable result as have been expended on futile attempts to meet the Massachusetts headlamp law, all maintenance costs and similar matters doubtless would be settled.

Sígnaling by means of ground and polished parabolic mirrors used in conjunction with highly concentrated filament incandescent lamps is beginning to be of importance, also the use of projection devices in aerial and trench warfare, for which purpose large numbers of searchlamps of different kinds are now being used abroad.

In the development of mirror backings, one notable feature already has been accomplished, that is, the electrolytic deposition of copper over the silver for protection and for increasing the heat radiation.

The illumination of advertising matter presents another large field for scientifically designed projection, and without doubt much will be accomplished in this direction. In street lighting, too, further improvements may be expected, especially along the lines of prismatic control of light. The lighting of many jarge outdoor areas will in the future undoubtedly be accomplishe by means of large sources of light used in conjunction with reflectors or prismatic glassware, or combinations of both, affording opportunity for the lluminating engineer to employ all his skill.

It is reasonable to suppose that advance in the art of interior illumination may be effected through the medium of improved projection apparatus. While noth. ing of a permanent nature other than the well know $r$ indirect system has as yet found favor, there is foor for thought in the lighting of interiors by projection.

\section{DISCUSSION.}

W. D'A. Ryan (communicated): I have reviewed the paper on "Evolution of Light P'rojection," by Mr. C. A. B. Halvorson and Mr. R. B. Hussey with profound interest, and wish to add my congratulations to Messrs. Halvorson and Hussey and to the Society in securing this contribution. There is very little that I could add of importance.

While it is clearly not the intention of the paper to go into details in reference to installations, nevertheless it may be interesting to know to what extent projectors were used in some of the notable installations mentioned.

The Singer Tower illumination. in 1908 was produced with thirty 18-inch arc projectors on the facades and one 30-inch are projector on the flag. At Niagara Falls in 1907 the total beam candlepower for the various arc projectors use was approximately $1.115,000,000$. At the Hudson-Fulton celebration, 1,000,000,000. The Electric Steam Color Scintillator at the Panama-Pacific International Exposition was 2,600,000,000. In 1912, the Buffalo General Electric Company's building was illuminated by direct diff used luminous ares on the facades and three 30 -inch arc projectors were mounted in the cupola on a revolving platform. Each projector rotated automatically to the right or left through a series of colored gelatine disth

The first attempt at the use of incandescent projectors in quantity was in connection with the PanamaPacific International Exposition. While these were not in operation until 1915, they were designed especially for this work in the fall of 1912. Approximately 300 flags were illuminate on the main group of buildings. One hundred with 13-inch arc projectors, and 200 with 500-watt incandescent projectors. In addition, there were 251 Seraphic Figures illuminated with 100-watt concentrated filament incandescent projectors. The balance of the projectors at the Exposition consisted of two hundred 18-inch arcs, twenty-five 30-inch ares and forty-eight 36 -inch arcs. This shows to what a great extent the projector was used in combination with other lighting units.

Another notable use of projectors was the illumination of the 90-foot Municipal Christmas tree with evergreen and bunting semi-circular background, in Chicago in 1915 and 1916. Both arc and incandescent projectors were combine and the tree was lighted alternately both in white and colors. Action was added to the spectacle by the use of 4,000 Novagem jewels taken from the Tower of Jewels at the San Francisco Exposition. The effect was wonderfully impressive.

\section{Tanning Fishing Nets}

AN account of the methods employed by the Dutch fishermen for preserving their nets. The usual procedure is to immerse the net in a hot solution of tannin for some time, and then to dry it. The author has found that if the net is then immersed for 15 minutes in a solution containing 1 per cent of copper sulphate and 0.7 per cent of ammonia, and again dried, the durability is much increased. After this treatment, it is important for the net to be used for fishing as soon as possible. The method is also adapted to the preservation of othe forms of netting.-W. Томввоск in Chem. Weekblad. 